\title{
Quality of life in patients with mild acute brain injury and their carers' needs in Greece
}

\author{
Evgenia Stasinopoulou, Margarita Giannakopoulou, Georgios Fildisis, Maria Kalafati, Chryssoula Lemonidou \\ Faculty of Nursing, School of Health Sciences, National and Kapodistrian University of Athens, Greece
}

Received: November 21, 2020

Accepted: January 12, 2021

Online Published: January 19, 2021

DOI: $10.5430 /$ cns.v9n1p39

URL: https://doi.org/10.5430/cns.v9n1p39

\begin{abstract}
Background: Investigating quality of life $(\mathrm{Q} Q \mathrm{~L})$ is of crucial importance for the scientific community as it could function not only as an indicator of prognosis and post-traumatic clinical and psychological changes in patients who have suffered from acute brain injury (ABI), but also as an indicator of the effectiveness of their treatment and social rehabilitation. In addition, it can highlight changes in the carer's health, social life and well-being. This study examined the QoL of patients following ABI and the needs of their carers.

Material and methodology: This study was conducted in patients suffering from ABI, who were admitted to the General Hospital of Attica "KAT" and to the National Rehabilitation Center and on their carers. Data collection including demographics and Quality of Life After Brain Injury Questionnaire (QOLIBRI) and the Family Needs Questionnaire (FNQ) was performed during patients' rehabilitation, while six months after release, a follow-up survey was conducted using the same questionnaires. Statistical analysis of data was performed using SPSS.

Results: We analysed 50 patients with mild ABI (GCS $\geq$ of 13/15) during rehabilitation and six months after release and found that their QoL improves and is positively related to improvement of health status (i.e. in terms of thinking ability, QoL improves from $r=2.33, p<.01$ to $r=3.37, p<.001$ ). We also found that "Age" has the greatest impact on the patient's progress for recovery and the general QoL after ABI $(r=-0.423, p<.01)$. In addition, it was found that carers of patients with ABI are confronted with the burden of care, while they record both fulfilled and unmet needs regarding their individual needs (i.e. only for $30 \%$ of the sample the need for help in preparing them for the worst is met).

Conclusions: Our study confirms previous findings that underline that ABI has a major impact on QoL of both patients and their carers providing them with long-term daily care. Although it has been found that over time there is an improvement in the QoL of patients with $\mathrm{ABI}$, the absence of an official support network for carers from public health system, hospitals and rehabilitation centers may adversely affect the QoL of patients and their carers. Therefore, more structured, long-term family-wide monitoring and support is needed, focusing on identifying those at risk of social isolation and incomplete social networking.
\end{abstract}

Key Words: Quality of life, Acute brain injury, Quality of Life After Brain Injury Questionnaire, Family Needs Questionnaire

\section{INTRODUCTION}

Acute brain injury (ABI) is a serious public health problem in Greece and worldwide, not only because of its size, but also because it affects young people, working age population and the elderly. It causes cognitive, physical and behavioral disorders, burdens the health care system and may endanger patients' quality of life (QoL) and their families. In addition, a significant part of the population remains outside the productive and social process. ${ }^{[1]}$

Improving living conditions and the level of health care pro-

\footnotetext{
*Correspondence: Evgenia Stasinopoulou; Email: evgeniast@hotmail.com; Address: Faculty of Nursing, School of Health Sciences, National and Kapodistrian University of Athens, Greece.
}

Published by Sciedu Press 
vided has led to an increase in life expectancy, including patients who have suffered ABI. However, many of these patients face increasing physical, psychological, social and functional consequences, with increased personal and public costs. $^{[2]}$

In this context, QoL could serve not only as an indicator of prognosis and post-traumatic changes in patients with $\mathrm{ABI}$ but also of the effectiveness of treatment and their social rehabilitation. In addition, it can help bring about changes in carers' health status, social life and well-being.

As society seems to be unaware of the magnitude of ABI's socio-economic consequences, scholars consider it to be a "silent epidemic". ${ }^{[3]}$ In Greece, there are no established family programs or structured follow-up programs after acute craniocerebral injuries or strokes in the healthcare centers where patients are treated. This results in further difficulty in finding comprehensive findings about the QoL of both patients and their carers.

The theoretical approach used to explain how disease affects QoL was the theory of Social Function Production, ${ }^{[4-6]}$ highlighting how the symptoms and complications of illness or disability create binding constraints on the exercise of the means (activities, resources) to achieve functional goals. These constraints increase the cost (money, energy), make the achievement of operational objectives "costly", according to the criterion of cost-effectiveness, bring harm instead of benefit and therefore negatively affect a person's QoL. ${ }^{[7]}$ In addition, to provide a more holistic understanding of the effects of ABI on carers, family systems theory was chosen as the theoretical framework. ${ }^{[8,9]}$

Studies related to the analysis of QoL are particularly useful for nursing practice to assess the physical, mental and social consequences of diseases and treatments in people's daily lives. They are also useful to analyze the effects of treatments or diseases as perceived by patients, as well as to identify their needs for psychological, physical and social support during the illness. However, further investigation is needed for the case of patients with ABI and their carers. Thus, the aim of the study was to investigate patients' QoL after ABI and the needs of their carers.

\section{MethodS}

\subsection{Participants and setting}

The study was conducted on a sample of 50 patients with ABI, who were admitted to the General Hospital of Attica "KAT" and to the National Rehabilitation Center (NRC) as well as on 50 carers. Research lasted 18 months, the data collection was performed during patients' rehabilitation, while six months after release, a follow-up survey was conducted with the 50 patients. To participate in the study, patients and carers were required to meet the following inclusion criteria: 1) age 18 years or older, 2) able to read and understand Greek, 3) able to fill in the questionnaire and 4) ensuring their consent to be included in the research.

\subsection{Measurements}

We collected demographics and the characteristics of the patients including Glasgow Coma Scale (GCS), as well as the characteristics of the carers. The tools selected as suitable for conducting the study were the questionnaire for the Quality of Life After Brain Injury Questionnaire (QOLIBRI), ${ }^{[10]}$ and Family Needs Questionnaire (FNQ). ${ }^{[1]}$ In addition we asked for rest and sleep adequacy for carers and financial support at home after hospital discharge.

\subsection{Data analysis}

Descriptive statistics (frequency distribution, percentages, mean, median, standard deviation) and multivariate analysis (Cronbach's index, Pearson correlation coefficient, factor analysis) were used for data analysis. The Statistical Package of Social Sciences (SPSS) was used for statistical analysis. To test the reliability, a pilot study was conducted on a sample of ten people with the same characteristics as the sample of the main study. The pilot study did not show the need of any changes in the questionnaires. The validity of both the pilot and the main study was statistically tested using the Cronbach's index and proved to be statistically reliable.

\subsection{Ethical consideration}

Patients and carers received a document explaining the purpose of the study and the procedures used to ensure anonymity. To this end, participants would be assigned a code. Participants in the study had the right to withdraw from the research without consequence for their treatment, while they were afforded plenty of time to carefully consider their decision. Those who agreed to take part in the study were asked to sign an informed consent form that was then forwarded to the researchers.

\section{RESULTS}

\subsection{Patients' sample characteristics}

The sociodemographic characteristics of the 50 patients having mild ABI are shown in Table 1.

Most patients were females, married, high-school graduates, private employees and hospitalized for the first time for this reason and most of them for one month. There was also a relative uniformity of the sample, covering a wide range of ages, as each age group has its own needs and often respond differently to treatment. 
Table 1. Characteristics of study population

\begin{tabular}{|c|c|c|}
\hline Characteristics & & $\mathbf{N}(\%)$ \\
\hline \multirow{2}{*}{ Sex } & Females & $31(62)$ \\
\hline & Males & $19(38)$ \\
\hline Age (years) & Mean $\pm S D$ & $53.3 \pm 18.7$ \\
\hline Range & Min-Max & 19-89 \\
\hline \multirow{4}{*}{ Marital status } & Single & $19(38)$ \\
\hline & Married & $23(46)$ \\
\hline & Separated & $1(2)$ \\
\hline & Widowed & 7 (14) \\
\hline \multirow{5}{*}{ Educational level } & Primary school & $8(16)$ \\
\hline & Secondary school & $5(10)$ \\
\hline & High school & $21(42)$ \\
\hline & Technological institute & $6(12)$ \\
\hline & University & $10(20)$ \\
\hline \multirow{6}{*}{ Occupational status } & Civil servant & $4(8)$ \\
\hline & Private employee & $18(36)$ \\
\hline & Self-employed & $3(6)$ \\
\hline & Student & $2(4)$ \\
\hline & Unemployed & $6(12)$ \\
\hline & Retired & $17(34)$ \\
\hline \multirow{5}{*}{$\begin{array}{l}\text { Duration of } \\
\text { hospitalization }\end{array}$} & $1-4$ days & $4(8)$ \\
\hline & 1 week & $8(16)$ \\
\hline & 2 weeks & $14(28)$ \\
\hline & 3 weeks & 8 (16) \\
\hline & 4 weeks & $16(32)$ \\
\hline \multirow{2}{*}{$\begin{array}{l}\text { Hospitalization for a } \\
\text { similar problem }\end{array}$} & Yes & $3(6)$ \\
\hline & No & $47(94)$ \\
\hline \multirow{2}{*}{ Interview place } & KAT & $22(44)$ \\
\hline & NRC & $28(56)$ \\
\hline \multirow{2}{*}{$\begin{array}{l}\text { Treatment in a } \\
\text { rehabilitation center }\end{array}$} & Yes & $50(100)$ \\
\hline & No & - \\
\hline \multirow{3}{*}{$\begin{array}{l}\text { Glasgow Coma Scale } \\
\text { (GCS) }\end{array}$} & 13 & $1(2)$ \\
\hline & 14 & $2(4)$ \\
\hline & 15 & $47(94)$ \\
\hline
\end{tabular}

Note. $\mathrm{KAT}=$ Hospital; $\mathrm{NRC}=$ National Rehabilitation Center
Regarding GCS, all patients had mild head injury having a GCS $>$ of $13 / 15$. Specifically, the vast majority had a GCS of $15 / 15$ (94\%), while $2 \%$ and $4 \%$ had a GCS $13 / 15$ and GCS of $14 / 15$ respectively. Thus, we had a homogenous patient population having a mild $\mathrm{ABI}$.

\subsection{Patients' QoL}

Our data show that ABI has a major impact on the QoL of both patients and their carers making it difficult for them to integrate socially and professionally. In Table 2, we present the dimensions of QoL of patients with $\mathrm{ABI}$ over time showing an improvement after six months. Using multivariate analysis (Pearson Correlation, Spearman's rho Correlations) we found that, the factors that affect QoL positively were marital status $(r=0.311, p<.05)$; GCS $(r=0.346, p<.05)$ and negatively are educational level $(r=-0.282, p<.05)$ and previous hospitalization for a similar reason $(r=-0.289, p<$ $.05)$.

We also found that "Age" has the greatest impact on the patient's progress for recovery and the general QoL after ABI $(r=-0.423, p<.01)$. Finally, "gender" is related to patients' ability to manage their personal finances, with men being negatively affected by their loss of ability to manage them and with negative consequences for the assessment of their $\operatorname{QoL}(r=-0.186, p<.05)$.

\subsection{Carers' characteristics}

The sample of carers consisted of 50 persons, 42 female and 8 male, who provided unpaid care, the majority (72\%) of whom were first-degree relatives of patients while only $28 \%$ of carers were not first-degree relatives (see Table 3).

\subsection{Carers' needs and disease burden}

Our data show that carers of the patients with ABI face the burden that arises from provision of care, while they have both fulfilled and unfulfilled needs in terms of their individual needs.

Table 2. Patients' QoL at baseline and after six months

\begin{tabular}{lll}
\hline Factor & Mean $(\boldsymbol{S D})$ A Phase-baseline & Mean $(\boldsymbol{S D})$ B Phase 6 months after \\
\hline Thinking ability & $2.33(0.441)$ & $3.37(0.489)$ \\
Feelings about oneself & $2.08(0.516)$ & $3.25(0.689)$ \\
Functioning in everyday life & $0.57(0.731)$ & $2.26(0.680)$ \\
Social relationships & $2.83(0.626)$ & $3.24(0.628)$ \\
Emotions & $1.36(0.636)$ & $1.84(0.572)$ \\
Physical problems & $2.37(0.494)$ & $2.10(0.477)$ \\
\hline
\end{tabular}


Table 3. Carer's relationship with the patient

\begin{tabular}{ll}
\hline Relationship & N $(\%)$ \\
\hline Husband/Wife & $15(30.0)$ \\
Child & $9(18.0)$ \\
Parent & $12(24.0)$ \\
Other & $14(28.0)$ \\
\hline
\end{tabular}

Table 4. Factors' affecting carers' neeeds

\begin{tabular}{lll}
\hline Factor & Mean $($ SD) & Effect \\
\hline Psychological Support & $3.57(0.239)$ & Positive \\
Individual Needs & $2.73(0.274)$ & Negative \\
Support Network & $1.46(0.303)$ & Negative \\
Emotional Coverage & $2.27(0.519)$ & Negative \\
Reward-Acceptance & $2.04(0.443)$ & Negative \\
\hline
\end{tabular}

Using factor analysis and after the removal of the variables that were not statistically significant, we found that there were five factors with a statistically significant effect on the total number of responses received. These factors affected either positively or negatively carers' needs as shown in Table 4. The provision of care, ranging from physical assistance to psychosocial support, had a great impact on their psychology, emotional state, work, social burden (insecurity, loneliness, depression $)(r=-0.553, p<.05)$.

Carer's needs for adequate rest and sleep was not covered for $38 \%$ of them while $62 \%$ of them reported only partially satisfied further contributing to unsatisfied life and disease burden especially due to long-term care at home after hospital discharge. Also, $66 \%$ of our patients reported lack of financial support regarding rehabilitation programs, physiotherapy, counseling and work counseling after discharge. In addition, only $2 \%$ of the carers reported sufficient financial or legal advice, daily care, counseling, and nursing care at home. Finally, only $30 \%$ of the patients reported psychological and sentimental support preparing them in case that further problems emerge further contributing to whole disease burden.

\section{DisCussion}

Several studies in the past revealed on the one hand the heavy burden on both physical and psychological level of the patients and on the other hand, the heavy burden on carers. ${ }^{[12-14]}$ Our data showed that that the QoL of patients with mild ABI is significantly affected by their illness, making it difficult for them to integrate socially and professionally. However, in the long run all participants expressed an improvement of QoL, confirming those studies that emphasize that the gradual improvement of physical condition leads to positive changes in mental health, as well as people's QoL. ${ }^{[15]}$ Thus, positive changes are recorded in terms of the ability to think, feelings about oneself, functioning in daily life and social relationships.

However, in the assessment of patients with mild ABI in terms of satisfaction with those aspects of their social relationships, there is a negative change in the degree of satisfaction of patients' relationships with friends and partners. These negative changes, on the one hand, may be related to the changes that ABI brings to patients' daily lives and their potential inability to find or communicate with friends as before the event. On the other hand, results confirm other studies $^{[16,17]}$ that emphasize the problems and/or conflicts that occur in the marital relations during hospitalization and/or recovery after traumatic episodes.

Literature also suggests that patients with $\mathrm{ABI}$ assess caring for their mental and social status as important as caring for their physical condition. Regarding the degree of annoyance of patients with ABI with feeling sad or depressed, the negative change recorded confirms the findings of other studies that highlight the worsening of depressive states over time in patients with various disabilities. ${ }^{[18-20]}$

Regarding patients carers and their needs, we found that they face a heavy burden of caring. The problems associated with brain damage are very serious and require a lot of energy both physically and mentally from carers to be able to stand by the patients. Carers, as components of the family system, after the sudden event of ABI, adapt to the new situation which can be described as a new phase of life for the whole family and their social network.

Lack of psychosocial support of carers by specialists during patients' treatment and rehabilitation, lack of formal support network of carers from hospitals, rehabilitation centers or other official institutions generates strong negative emotions. This also has negative consequences in terms of their ability to remain optimistic about patients' future but also to prepare for the worst, confirming those studies that show that loneliness, insecurity, depression are common consequences of providing care to patients with $\mathrm{ABI} .^{[21,22]}$ Unmet needs from formal support networks forces carers to seek help from both their immediate family environment and the wider social circle of the patients to support and reward them for how well they treat and care for their patients. Thus, thanks to the family, as a social institution which still remains strong in Greece, but also to the informal solidarity among relatives and friends that is strongly reflected, the carers find the necessary support required to respond to the care, treatment and rehabilitation needs of the patients.

In addition, an interesting aspect of our research concerns 
the non-coverage from the public social security system of the necessary resources during treatment and rehabilitation, which highlights the high cost of private health care, thus confirming those studies that emphasize this "open wound" of the health system in Greece. ${ }^{[23]}$ The non-coverage of the necessary financial resources for themselves and their families confirms the assumption of paying a large enough amount of money for the treatment and rehabilitation of patients, which, to be covered, is taken from the needs of the other members of the household.

\subsection{Limitations}

This study presents a number of limitations. First, our analyses were based on a convenience sample that was not representative of the entire population of Greek ABI patients. Therefore, the results of this study cannot be generalized. Second, our design for carers provided a description at a given point in time only. Repeated measures would afford a more detailed representation of the relationships between the variables considered. Third, we used one instrument to measure patient QoL. The use of two instruments, one specific and one not, as recommended by several scholars, would have provided a more detailed picture of this element. ${ }^{[24]}$

However, results of this study can contribute to the relevant literature to the extent that they highlight the role of enhanced care and rehabilitation, holistic oriented to family. This is because an approach that focuses on the family (patient and carer) will not only make patients and carers more prepared for the future, but will prevent the great burden they both feel in the long run.

\section{Conclusions}

The QoL of patients with ABI is significantly affected by the negative physical and psychological consequences of ABI. However, over time, positive changes are recorded in patients' assessment of QoL. This is due to the objective clinical improvement but also and most importantly to the environment of the family through which carers provides their support.

For carers themselves, however, the degree of burden due to long-term care is high. In addition, the absence of a formal support network for carers on behalf of public health system, hospitals, rehabilitation centers or other official institutions, negatively affects the QoL of patients and their carers.

Therefore, structured long-term follow-up of the whole family, focusing on identifying those at risk of social isolation and exclusion, is essential. Thus, policy-makers should focus on incorporating ABI related issues and costs in public security system, facilitate and improve access and highlight the importance of rehabilitation process after ABI for both patients and their carers. ${ }^{[25]}$ To this, actively engaging nurses to provide long term support (i.e. home care) covered by the public insurance system could play a significant role.

However, we suggest that a more structured, long-term family-wide monitoring is needed, focusing on identifying those at risk of social isolation and incomplete social networking for prompt and adequate support.

\section{CONFLicts OF InTEREST Disclosure}

The authors declare they have no conflicts of interest.

\section{REFERENCES}

[1] Dijkers MP. Quality of life after traumatic brain injury: a review of research approaches and findings. Arch Phys Med Rehabil. 2004; 85(Suppl 2): S21-35. PMid: 15083419. https://doi.org/10.1 016/j.apmr.2003.08.119

[2] Zaloshnja E, Miller T, Langlois JA, et al. Prevalence of long-term disability from traumatic brain injury in the civilian population of the United States, J Head Trauma Rehabil. 2005; 23: 394-400. PMid: 19033832. https://doi.org/10.1097/01.HTR.00003 41435.52004.ac

[3] Roozenbeek B, Maas AI, Menon DK. Changing patterns in the epidemiology of traumatic brain injury. Nat Rev Neurol. 2013; 9: 231236. PMid: 23443846. https://doi.org/10.1038/nrneurol.2 013.22

[4] Lindenberg S. Continuities in the theory of social production functions. In S. Lindenberg and H. B. G. Ganzeboom (ed.). Verklarende sociologie: opstellen voor Reinhard Wippler. Amsterdam: Thesis Publishers; 1996; 169-184.

[5] Lindenberg S. Social rationality versus rational egoism. In J. Turner (ed.). Handbook of Sociological Theory. New York: Plenum; 2001;
635-668 p. https://doi .org/10.1007/0-387-36274-6_29

[6] Minasidou E, Lemonidou CH. Quality of Life of Patients with chronic diseases and the Theory of Social Activities Production (SAP). Nursing. 2005; 44(2): 202-211 (in Greek).

[7] Sarris M, Soulis S, Yfantopoulos I. Social production functions theory. Archives of Hellenic Medicine. 2001; 18(3): 230-238 (in Greek)

[8] Rosenthal M, Young T. Effective family intervention after traumatic brain injury; theory and practice. Journal of Head Trauma Rehabilitation. 1988; 3: 42-50. https://doi.org/10.1097/00001199-1 98812000-00007

[9] Leaf LE. Traumatic brain injury: affecting family recovery. Brain Inj. 1993; 7: 543-6. PMid: 8260958. https://doi.org/10.3109/02 699059309008182

[10] Von Steinbüchel N, Wilson L, Gibbons H, et al. Quality of life after brain injury (QOLIBRI): Scale validity and correlates of quality of life. Journal of Neurotrauma. 2010(a); 27: 1157-1165. PMid: 20210602. https://doi.org/10.1089/neu.2009.1077

[11] Kreutzer J, Marwitz J. The family needs questionnaire. Richmond: the National Resource Center for traumatic brain injury, Medical College of Virginia; 1989. 
[12] Thomsen IV. The patient with severe head injury and his family. A follow-up study of 50 patients. Scand J Rehabil Med. 1974; 6: 180-3.

[13] McCarthy ML, Serpi T, Kufera JA, et al. Factors influencing admission among children with a traumatic brain injury. Acad. Emerg Med. 2002; 9: 684-93. PMid: 12093708. https://doi.org/10.1197/ aemj $\cdot 9 \cdot 7 \cdot 684$

[14] Madikians A, Giza C. A Clinician's Guide to the Pathophysiology of Traumatic Brain Injury. Indian J. of Neurotrauma. 2006; 3(1). https ://doi.org/10.1016/S0973-0508(06)80004-3

[15] Center for Disease Control and Prevention. Physical activity for everyone. The importance of physical activity. Why should I be active? US: Centers for Disease Control and Prevention; 2005.

[16] Kreuter M, Dahllof AG, Gudjonsson G, et al. Sexual adjustment and its predictors after brain injury. Brain Inj. 1998; 12: 349-368. PMid: 9591141. https://doi.org/10.1080/026990598122494

[17] Gill CJ, Sander AM, Robins N, et al. Exploring experiences of intimacy from the viewpoint of individuals with traumatic brain injury and their partners. J Head Trauma Rehabil. 2011; 26(1): 5668. PMid: 21209563. https://doi.org/10.1097/HTR.0b013e 3182048 ee 9

[18] Vickery C, Gontkovsky S, Caroselli J. Self-concept and quality of life following acquired brain injury: A pilot investiagtion. Brain Injury. 2005; 19: 657-665. PMid: 16195178. https ://doi.org/10.108 $0 / 02699050400005218$
[19] Wood RL, Rutterford NA. Long-term effect of head trauma on intellectual abilities: A 16-year outcome study. Journal of Neurology, Neurosurgery \& Psychiatry. 2006; 77: 1180-1184. PMid: 16772355. https://doi.org/10.1136/jnnp. 2006.091553

[20] Landau J, Hissett J. Mild traumatic brain injury: impact on identity and ambiguous loss in the family. Families, Systems and Health 2008; 26: 69-85. https ://doi.org/10.1037/1091-7527.26.1 .69

[21] Freund J, Hayter C, McDonald S, et al. Cognitive communication Disorders following Traumatic Brain Injury. A practical guide. Austin Texas: pro-ed; 1994.

[22] Visser-Meily A, Post M, van de Port I, et al. Psychosocial functioning of spouses in the chronic phase after stroke: Improvement or deterioration between 1 and 3 years after stroke? Patient Educ Couns. 2008; 73(1): 153-158. PMid: 18450411. https : //doi.org/10.1016/j.pec.2008.03.011

[23] Economou CH, Kaitelidou D, Karanikolos M, et al. Greece. Health system review. World Health Organization, on behalf of the European Observatory on Health Systems and Policies. 2017.

[24] Danquah FVN, Meininger J, Zimmerman L, et al. Frequency, severity and distress of dialysis-related symptoms reported by patients on hemodialysis. Nephrology Nursing Journal. 2010; 37: 627-638.

[25] Wolfenden B, Grace M. Returning to work after stroke: a review. International Journal of Rehabilitation Research. 2009; 32: 93-97. PMid: 19158652. https://doi.org/10.1097/MRR.0b013e32 $8325 a 358$ 